\title{
Realizing Learning in the Workplace in an Undergraduate IT Program
}

\author{
Anne Venables \& Grace Tan \\ Victoria University, Melbourne, Victoria, Australia
}

Anne.Venables@vu.edu.au Grace.Tan@vu.edu.au

\section{Executive Summary}

Higher education programs need to prepare their graduates for the practical challenges they can expect to face upon entering the workforce. Students can be better prepared if their academic learning is reinforced through authentic workplace experience, where the link between theory and professional practice can be realized. Increasingly, such learning in the workplace is being seen as an integral part of the university curricula as evidenced through the implementation of the Learning the Workplace \& Community (LiWC) Policy at Victoria University, Australia. This policy mandates a minimum of $25 \%$ content and assessment of all academic programs be related to work-integrated learning.

Recognizing the need for authentic workplace experience in the IT undergraduate program, a review found that the existing work-related learning component accounted for only half the required 25\% LiWC commitment. Currently, the LiWC component is an industry-based capstone project that spans two semesters in the final year of study. These projects allow students to work on real-life software development tasks where they experience the practical challenges of building software systems whilst appreciating the needs of a business client. In a search of the literature, campus-located industry projects were identified as one of the two most common workrelated learning experiences in IT programs, the other being internships sited in the workplace.

By retaining the current project-based component, it was decided to add an internship to the program to further bolster the student learning experience and graduate outcomes. This paper details the existing program structure and explores two possible implementations for the achievement of the LiWC policy. The first approach necessitates the addition of one academic year of cooperative education internship to be placed strategically between the current second and third years. Alternatively, the second proposal sacrifices several elective units to accommodate a final semester internship experience. The paper discusses both alternatives against various issues under consideration: staffing and administration, assessment, industry partnerships, professional accreditation and its impact upon differing cohorts of students.

Keywords: IT education, computing education, learning in the workplace, internship

Material published as part of this publication, either on-line or in print, is copyrighted by the Informing Science Institute. Permission to make digital or paper copy of part or all of these works for personal or classroom use is granted without fee provided that the copies are not made or distributed for profit or commercial advantage AND that copies 1) bear this notice in full and 2) give the full citation on the first page. It is permissible to abstract these works so long as credit is given. To copy in all other cases or to republish or to post on a server or to redistribute to lists requires specific permission and payment of a fee. Contact Publisher@InformingScience.org to request redistribution permission.

\section{Introduction}

The nature of higher education is changing. Traditionally, the teaching and learning has been organized around disciplinary knowledge and governed by academic interests. However, pragmatic demands made by increasing numbers of students, who view their further studies as part of the natural transition process 
from school to work, have influenced a shift in program focus to the development of more workrelated skills (Griffiths, 2001; Krause, Hartley, James, \& McInnis, 2005). In Australia, graduates' rankings of program relevance to employability outcomes are one of the key indicators for deciding government funding to universities. Therefore, it is in the interest of universities to actively promote the development of generic and work-related skills in their graduates and to document and measure their outcomes (Oliver, Jones, Ferns, \& Tucker, 2007). In fact, for some institutions, the workplace is being seen more favorably as a legitimate site for contextualized learning that can bridge the gap between theory and practice and promote the development of desirable core graduate attributes.

The workplace provides opportunities for students to learn in and through work rather than learning about and for work (Keating, 2006), and, although this has been recognized traditionally in some professions such as engineering, nursing, and teaching, it is not the normal mode of delivery for most university programs. Such programs recognize that "working knowledge is 'rarely codified in text books, formal training programs, competency standards or procedures manuals and is more likely to be developed within the context and environment of the immediate workplace"" (Chappell, n.d., p. 6 as cited by Keating, 2006, p. 3). Knowledge that can be applied is far more valuable to students than explicit academic knowledge in that it is contextual, social, and situation specific (Symes \& McIntyre, 2000). Calway (2006) details five generic models for incorporating work-integrated learning into higher education programs: Project-based experience, Contextual learning, Supervised experience, Work-integrated learning and Joint industry/university courses. These models can be implemented through a diversity of learning theories including active, experiential, services, vocational, and situated. Calway further reiterates that regardless of the learning theory employed, imperatives such as work readiness, life-long learning, human and social potential, internationalized thinking, knowledge transfer, and a career development focus should be expressed within the educational structure.

Learning in the workplace (LiW) programs are designed to capitalize upon the inherent link between theory and its place in professional practice. By using the resources made available by organizations, a broad spectrum of university endorsed programs and opportunities become available to learners. Programs range from lightly tailored versions of existing courses delivered in the workplace to those that depart significantly from the traditional disciplinary offerings of tertiary studies (Boud, Solomon, \& Symes, 2001). This paper explores current practice of LiW in information technology (IT) and computing programs before discussing the current situation at Victoria University for the undergraduate IT program. An examination and revision of the existing program structure will be detailed and an extension of work contextualized learning to improve graduate skill sets will be proposed. Finally, the advantages of adopting this approach will be discussed.

\section{LiW in IT and Computing Programs}

A professional skills gap has been identified in that IT and computing programs do not prepare students sufficiently to cope with the practical challenges in current technologies adoption (Finkelstein \& Hafner, 2002; Taft, 2007). Employers want graduates with technical knowledge, intellect, and a willingness to learn. Research on employer satisfaction with graduate skills has found that computer science graduates lack problem solving and business communication skills (AC Nielsen Research Services, 2000; Harvey, Moon, Geall, \& Bower, 1997). It is widely recognized that computing undergraduate studies do not adequately prepare students for proficiency in the workforce where they need strong communication skills and business aptitude (Begal \& Simon, 2008). Therefore, the curriculum should ensure that students are prepared effectively for future employment by responding to the education and training needs of industry and the community. 
In a case study tracking novice software developers at Microsoft, Begal and Simon (2008) found that the new graduates were surprised to find that soft skills were a major component of their new jobs. Therefore it is essential that any IT program should focus on the balance between vocational and intellectual demands in order to enhance graduate employment prospects. Fang, Lee, and Huang (2004) are of the opinion that the benefit of work integrated learning is more valuable to new IT graduates given the current job market since fresh graduates from internship programs generally receive higher entry-level compensation and encounter a shorter period in obtaining their first position as compared to those without an internship experience. Additionally, the inclusion of a specific work placement component in an IT program benefits the students through exposure to technical and business mentoring and to current industry standards, as well as an opportunity to clarify career goals (Calway, 2006; Trigwell \& Reid, 1998).

To embed workplace learning, some IT and computing programs incorporate a mandatory workintegrated learning internship within the curriculum as a mechanism to improve the technical capabilities of their students. Internships foster maturity in students' approach to work, helping promote career planning and goals for learners, and there is considerable empirical evidence to support that participating students are advantaged in obtaining employment more quickly than their non-internship peers. Often, the internship experience offers both the students and employers opportunities to 'try before they buy' into an on-going work relationship (Carpenter, 2003; Poppins \& Singh, 2005). However, to our knowledge there has not been reported in the literature the detailed implementation and assessment with respect to work integrated learning in these programs.

Alternatively in IT and computing programs, a more common practice is to include a final year industry-based project that gives students the opportunity to work in a team on a real-life software development problem. Students benefit by being engaged with real problems for real industry clients whilst being supported by academic supervisors. The project unit provides opportunities for independent self-directed learning and realistic experiences in an environment that allows for experiential learning (Keogh, Sterling, \& Venables, 2007; Lynch, Heinze, \& Scott, 2007).

\section{Our Situation}

A significant part of the IT degree at Victoria University is an industry-based capstone project that spans two semesters in the third and final year of study. These projects give students the opportunity to work on real-life software development tasks where they experience the practical challenges of building software systems whilst appreciating the needs of a business client. Students need to use their technological knowledge and they develop their communication, teambuilding, and problem solving skills. When dealing with clients, students develop negotiation and listening abilities and they hone their presentation and marketing skills. Therefore, the Project unit is studied with a co-requisite unit in Professional Communication, which is designed to further develop the necessary advanced written and oral communication skills.

These project-centered units (shaded $40 \%$ gray) are shown within the current program structure, illustrated in Figure 1. Overall, the current IT program comprises 24 units of study over six academic semesters. In the first year, students are introduced to core subjects by covering the IT skills at an introductory level (not shaded), the second year content is at an intermediate level (shaded 10\% gray) followed by advanced IT knowledge in the final year of the degree (shaded $25 \%$ gray). Elective units at suitable levels provide students with the flexibility to pursue their particular computing strengths and interests. The current structure satisfies the Australian Computer Society (ACS) Professional level of accreditation which is pivotal for all Australian IT programs, in that it is a vital quality assurance measure and it enhances program marketability. This accreditation level specifies that there is a minimum of one equivalent full time year of IT mate- 
rial, with at least one third of this material being studied at an advanced level to provide extra breadth and depth of IT knowledge (ACS, 2003).

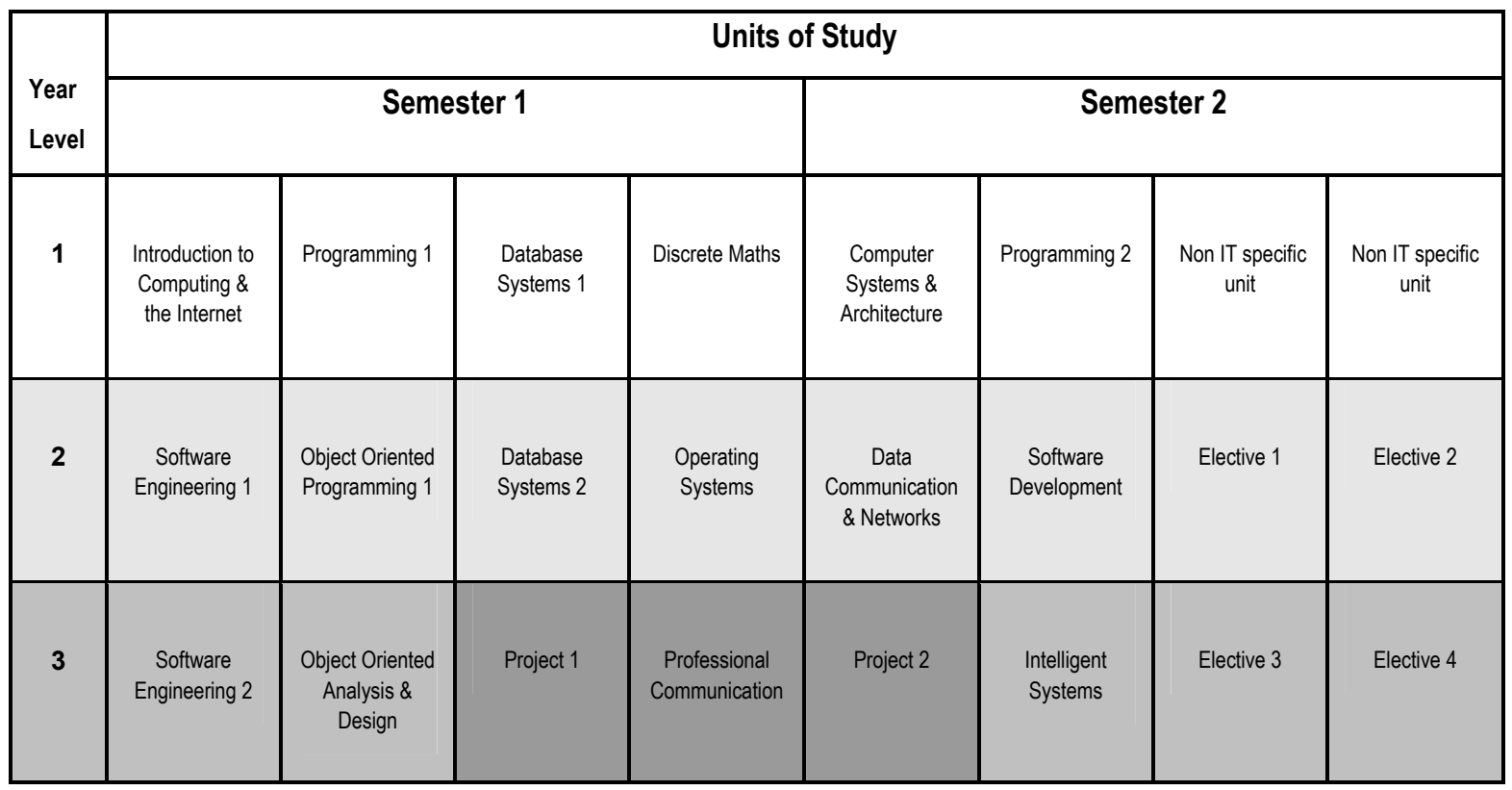

Figure 1: Current IT program structure

At Victoria University a new initiative was launched in 2007 to ensure that all teaching programs would "create job ready and community aware graduates whose courses have at least $25 \%$ learning in the workplace, including opportunities for service learning in the community" (Aitkin \& Mitchell, 2007). To implement this initiative, a new Learning in the Workplace and Community Policy (LiWC) has as its goal that workplace contextual learning be embedded in all course deliveries. Scheduled for progressive implementation by 2010 , the policy requires that a minimum of $25 \%$ of program content and assessment must be related to work integrated learning. The task to realize this policy has resulted in an extensive review of existing approaches to learning and teaching in all programs across the university and it poses significant challenges for the Information Technology (IT) program in the School of Computer Science and Mathematics. Currently, the LiWC practice amounts to only half of the required $25 \%$ LiWC component, and it is realized by the project and Professional Communication units ( 3 out of 24 units).

\section{Possible Implementations for Realizing LiW}

The scheduled implementation of the LiWC Policy, to incorporate a minimum of $25 \%$ of work integrated learning in course content and assessment, has provided the impetus for the undergraduate IT program review. An overall assessment of the program was made before focusing on the work related learning opportunities. As project-based learning has been an important lynch pin of our traditional IT program, the University mandate to increase the overall proportion of $\mathrm{LiW}$ experience was seen as an opportunity to explore other approaches to further strengthen the preparedness of graduating students for life in industry. By retaining the current project-based units, which promote graduate outcomes through the development of generic and technical skills, it is proposed to add in an alternate additional work-based option to further bolster this experience. As indicated earlier, work-based internships provide realistic and authentic work practice with the associated measurable employment benefits for IT students at other universities (Carpenter, 2003; Poppins \& Singh, 2005). Therefore, it is proposed that the work related content of the 
program be comprised of two distinct, yet complementary, parts: the existing course offering with project-based learning and an internship component which will further enhance the project-based learning experience. The learning objective of this approach is to provide a more complete curriculum through the blending of two distinct $\mathrm{LiW}$ experiences.

The incorporation of this additional work-based component into the current IT program can be implemented in two possible ways. Firstly, the length of the program could be extended by an internship experience, or alternatively, the normal program duration could remain if other units were sacrificed to accommodate it. The first approach is shown in Figure 2 where the introduction of an additional one-year long co-operative education internship is placed strategically between the current second and third years. It is expected that this industry experience will influence student choice of electives and students' overall approach to their capstone project task upon their return from the internship experience. Alternatively, through the replacement of several elective units and minor unit order rearrangement, it is possible to furnish the program with a final semester workplace experience, as illustrated in Figure 3. In this proposal, the five semesters of the previous program content is retained. Note that the mandatory units in the fifth semester, the capstone project (albeit now reduced to one unit) and Professional Communication unit remain in the course and help prepare students for the internship. This second proposal will impact upon the traditional academic content, and it will need to be evaluated carefully to weigh the benefits of the improved LiW experience against the cost of its implementation.

The choice of the most appropriate strategy requires careful consideration of several issues including: program structure, administration and duration, unit deliveries, assessment practices, industry alliances, professional accreditation requirements, and concerns of local students and international students together with partnering institutions and pathway arrangements.

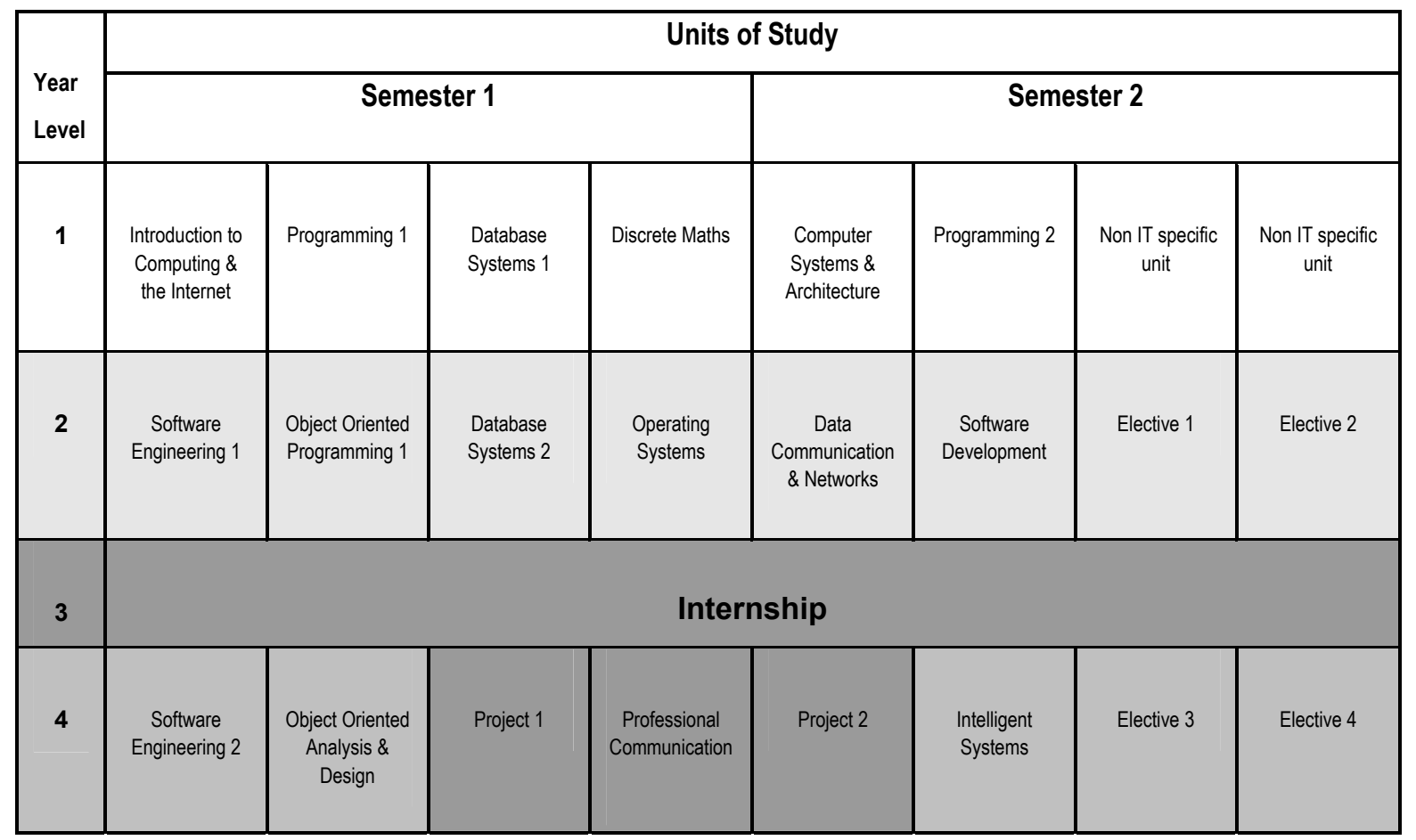

Figure 2: A proposed course structure to achieve 32\% LiWC experience over a 4-year program 


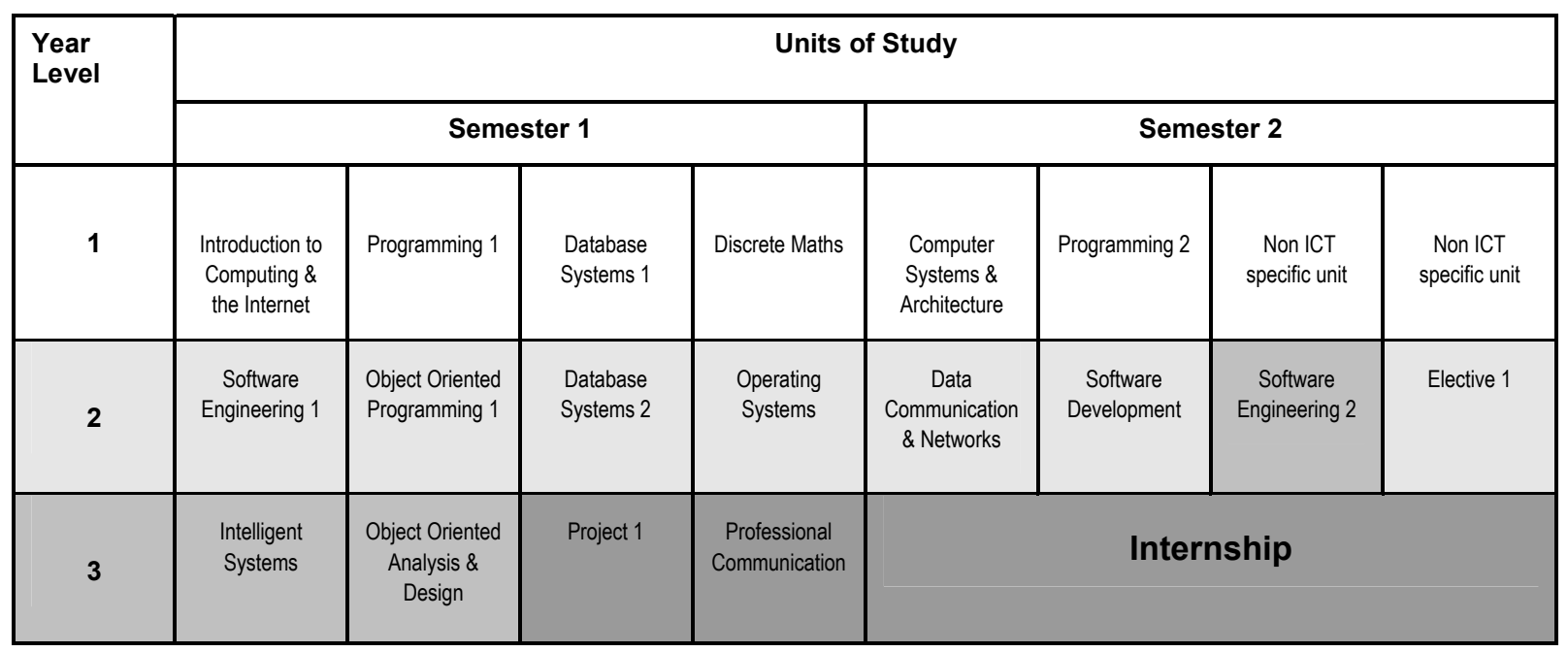

Figure 3: A proposed course structure to achieve 25\% LiWC experience over a 3-year program

\section{Key Issues}

\section{Staffing and Administration}

The addition of an internship to any program brings with it a set of costs, irrespective of the actual length of internship. One of the main costs is the provision of a dedicated work placement coordinator to assist in the selection of appropriate LiW placements. The coordinator will manage the practical aspects of facilitating work placement and, importantly, in cases where demand exceeds supply of placements, the placement coordinator has the additional pressure to find suitable placements to cater for such shortages. They need to display both pedagogic and administrative capabilities to manage these internships whilst considering the relevancy of the work experience to be gained by students and, together with academic staff, they will be responsible for assessing the validity and quality of each placement.

The roles of the coordinator and academic staff involved in the internship program are quite different from their traditional classroom teaching where they act as a facilitator and mentor to students. They may even be called upon to act as a mediator between participating students and industry partners (Boud, 2003; Keating, 2006; Waters, 2005). There are issues of academic staff preparedness for these roles and different ways of interacting with students and workplace staff. Suitable training and ongoing support is a necessary precondition for the implementation of any internship program.

\section{Assessment}

Irrespective of the duration and placement of the internship, the work placement component will require new assessment practices to be put in place. As each student experience will be unique, the challenge will be to find assessments that place value on a disparate range of student workplace experiences. The assessment should be contextualized for each site and student pairing and criteria for assessing the validity and quality of each placement together with the merit of students' LiW experiences will need development.

Since assessment drives learning outcomes (CSHE, 2007; McDowell, 1995), there needs to be alignment of assessment tasks to planned learning outcomes. Assessment should promote the development of problem-solving skills, personal development, and social skills within a community 
or industry focused setting. Tasks have to accurately reflect the workplace environment and encourage students to draw upon their formal learning and use it to interrogate workplace practices. Assessments that encourage broad capabilities rather than more narrow learning objectives should be employed by educators to ensure that students actually learn in the workplace (Keating, 2006). Suitable assessment strategies such as journals, learning plans and contracts, work reports, and performance portfolios have all been reported in the literature as suitable in preference to standard academic assessments of exams and essay writing (Klenowski, 2002; Stephenson \& Yorke, 1998). The grading of such assessments needs to be fair and flexible to take into account student progress and skill acquisition throughout the work placement.

\section{Industry Partnerships}

Finding suitable workplace industries and supervisors is a major challenge for any university implementing an internship program. Good industry partnerships are pivotal to the implementation of work placements where there needs to be a steady and reliable supply of LiW opportunities for large numbers of students.

A major need for managing industry partnerships is that the individual responsibilities are unambiguously detailed in clear guidelines and given to all parties involved. The role of workplace staff is vital in providing quality supervision of students. Their task is to foster an environment conducive to learning, facilitate learning opportunities connected to day-to-day practice in the workplace, and promote self direction and independence in their charges.

\section{Accreditation}

Currently, the course is fully accredited at the highest professional level as it comprehensively covers the core body of computing knowledge as outlined by the Australian Computer Society (ACS, 2003). However, the issue of Professional accreditation requirements needs to be revisited when the possible inclusion of the internship in a program is done by sacrificing electives as shown in Figure 3. A careful analysis of ACS program accreditation requirements has been previously mapped and both proposals comply with full Professional status (Tan \& Venables, 2008). In fact, the addition of an internship within the program matches the emphasis that the ACS places upon contextual IT and social competencies needed by graduates in their professional practice.

\section{Implications for Students}

The pedagogy of workplace learning is a form of experiential learning that is underpinned by the tenet of constructivism where students learn through their experiences rather than from direct transmission of material through their teachers. This is particularly important at Victoria University as the majority of students attend for vocational preparation, and, often, they are the first generation of their families to engage in tertiary studies. The duration of the course is likely to be a major decider for many students when selecting an IT program to study. A four-year study program maybe unattractive to students due to the time and financial costs associated with an additional one-year internship.

This issue has the potential to have different impacts for each student cohort. The additional expenses incurred by a further year of study and lodging impact most significantly upon international students. Consideration needs to be given to an option of allowing international students to undertake the internship program in their home countries, and if allowed, this option will require additional resources. Similar concerns are raised for offshore partner institutions involved in the delivery of the IT course. Incorporating LiW in offshore locations will have implications including issues such as overseas jurisdictions, contractual arrangements and the availability of re- 
sources and support (Kay \& Russell, 2008). For those students returning to studies but already working in the IT industry, there needs to be provision so that they maybe able to receive recognition of work related experiences for the LiW components of the program.

\section{Summary}

Increasingly, learning in the workplace has been institutionalized and is being seen as an integral part of the university curricula as evidenced through the implementation of the LiWC policy at Victoria University. The computing programs at Victoria University continue to face the same local, national, and international challenges as do other higher education providers of IT programs within Australia as it strives to maintain relevancy in its program offerings. Recognizing the need for authentic workplace experience in our IT undergraduate program, a recent review proposed the introduction of an additional work-based learning component, through an internship, to complement the existing project-based experience. Two approaches for achieving an internship were presented and discussed against various key issues of staffing and administration, assessment, industry partnerships, accreditation, and implications for students. Although common challenges have been identified in both strategies of internship implementation, it is the overall effect of program duration on students that suggests that the second approach that maintains a three-year program will be a better attractor for students entering the program. Either way, introduction of

an internship to the IT program gives students the opportunity to sharpen their generic and IT specific skills thereby enriching their learning experiences and enhancing their employment prospects.

\section{References}

AC Nielsen Research Services. (2000). Employer satisfaction with graduate skills. Research Report 99/7. Department of Education, Training and Youth Affairs (DETYA).

ACS - The Australian Computer Society. (2003). Accreditation of courses at the professional level Guidelines for applicants. ISBN 090992564 X.

Aitkin, D., \& Mitchell, J. (2007). The answer is already here. A discussion paper on Victoria University's approach to teaching and learning in the context of making VU. An internal university report.

Begal, A., \& Simon, B. (2008). Novice software developers, all over again. Proceedings of ICER Conference 2008, 6-8 September 2008, Sydney, Australia. Retrieved September 2008 from http://www.newcastle.edu.au/conference/icer2008/Files/icer03-begel.pdf

Boud, D. (2003). Combining work and learning: The disturbing challenge of practice. Proceedings of the Conference on Experiential-Community-Workbased: Researching Learning Outside the Academy, Glasgow, Scotland.

Boud, D., Solomon, N., \& Symes, C. (2001). New practices for new times. In D. Boud \& N. Solomon (Eds.), Work-based learning: A new higher education? (pp. 3-17). Buckingham, UK: The Society for Research into Higher Education \& Open University Press.

Carpenter, D. A. (2003). Meaningful information systems internships. Journal of Information Systems Education, 14(2), 201-210.

Calway, B. A. (2006). What has work-integrated learning learned? - A WIL philosophy. Industry and Higher Education. UK: IP Publishing. Retrieved April 10, 2008, from http://centreforefs.com/resources/b_calway_2006.pdf

Chappell, C. (n.d.). Changing pedagogy: Contemporary vocational learning. The Australian Centre for Orginisation, Vocational and Adult Learning, Sydney. 
CSHE. (2007). Core principles of effective assessment. Centre for the Study of Higher Education, University of Melbourne. Retrieved August 13, 2007, from http://www.cshe.unimelb.edu.au/assessinglearning/docs/CorePrinciples.pdf

Fang, X., Lee, S., \& Huang, W. (2004). Critical factors affecting job offers for new MIS graduates. Journal of Information Systems Education, 15(2), 189-204.

Finkelstein, L., \& Hafner, C. (2002). The evolving discipline(s) of IT (and their relation to computer science): A framework for discussion. Retrieved October 2007 from http://www.cra.org/Activities/itdeans/finkelstein.pdf

Griffiths, T. (2001). Work experience as an education and training strategy: New approaches for the $21^{\text {st }}$ century: Final Report. University College London, Institute of Education.

Harvey, L., Moon, S., Geall, V., \& Bower, R (1997). Graduates' work: Organisation change and students' attributes. Birmingham: Centre for Research into Quality (CRQ) and Association of Graduate Recruiter (AGR).

Kay, J., \& Russell, L. (2008). Learning in the workplace and community - A discussion paper to inform review of policy. An internal discussion paper, Victoria University.

Keating, S. (2006). Learning in the workplace: A literature review. Melbourne: Victoria University.

Keogh, K., Sterling, L., \& Venables, A. (2007). A scalable and portable structure for conducting successful year-long undergraduate software team projects with real clients. Journal of Information Technology Education, 6, 515-540. Retrieved from http://jite.org/documents/Vol6/JITEv6p515-540Keogh288.pdf

Klenowski, V. (2002). Developing portfolios for learning and development. London and New York: Routledge Falmer.

Krause, K., Hartley, R., James, R., \& McInnis, C. (2005). The first year experience: Findings from a decade of national studies. Canberra: Department of Education, Science and Training.

Lynch, K., Heizne, A., \& Scott, E. (2007). Information technology team projects in higher education: An international viewpoint. Journal of Information Technology Education, 6, 181-198. Retrieved from http://jite.org/documents/Vol6/JITEv6p181-198Lynch354.pdf

McDowell, L. (1995). The impact of innovative assessment on student learning. Innovations in Education and Training International, 32(4), 302-313.

Oliver, B., Jones, S., Ferns, S., \& Tucker, B. (2007). Mapping curricula: Ensuring work-ready graduates by mapping course learning outcomes and higher order thinking skills. Proceedings of the ATN EAC2007 Conference, 29-30 November, 2007, Brisbane, Australia, pp. 103-109.

Poppins, P., \& Singh, M. (2005). Work integrated learning in information technology education. In IFIP International Federation for Information Processing Series, 182, 223-230. Retrieved September 2008 from http://www.springerlink.com/content/037142p6016k6k64/fulltext.pdf

Stephenson, J., \& Yorke, M. (1998). Creating the conditions for development of capability. In J. Stephenson \& M. Yorke (Eds.), Capability and quality in higher education. London, U.K.: Kogan Page.

Symes, C., \& McIntyre, J. (2000). Working knowledge: The new vocationalism and higher education. Buckingham: Society for Research into Higher Education \& Open University Press.

Taft, D. (2007). Programming grads meet a skills gap in the real world. Retrieved September 2007 from http://www.eweek.com/article2/0,1895,2178319,00.asp

Tan, G. \& Venables, A. (2008). The introduction of a 'learning in the workplace' component for an undergraduate IT Program and its impact on professional accreditation. Proceedings of EDUCOM 2008Conference, 19-21 November 2008, Khon Kaen, Thailand. pp. 474-480.

Trigwell, K., \& Reid, A. (1998). Introduction: Work-based learning and the students' perspective. Higher Education Research \& Development, 17(2), 141-158. 
Waters, M. (2005). Pedagogy in VET: A background paper. Melbourne, Australia: TAFE Development Centre.

\section{Biographies}

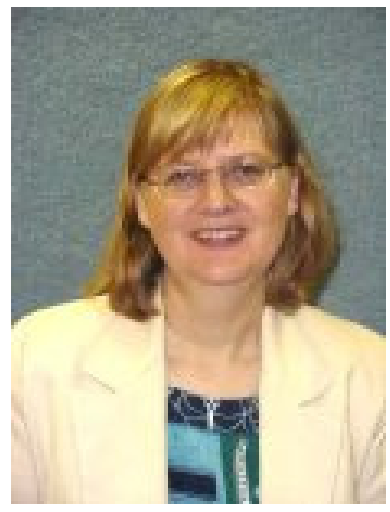

Anne Venables lectures in Computer Science and Information Technology at Victoria University, Melbourne, Australia. She has research and teaching interests in innovations in computing education and the application of intelligent systems in biological systems.

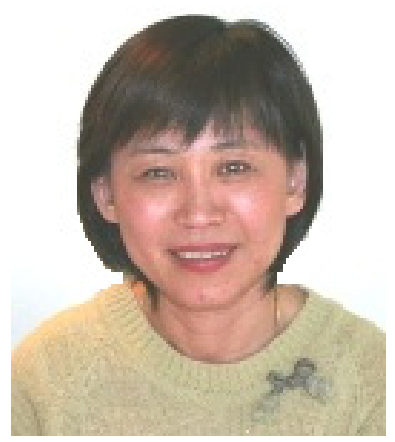

Grace Tan is a senior lecturer in Computer Science at Victoria University, Melbourne, Australia. Her research interests include investigations of innovative teaching methods, the development of graduate attributes, and issues related to female students in computing courses and Grace has published in these areas. 